\title{
Effects of the association of antifungal drugs on the antimicrobial action of endodontic sealers
}

Paulo Henrique WECKWERTH ${ }^{(a)}$

Fellipe Lombardo de Souza LIMA(a)

Vanessa Raquel GREATTI(a)

Marco Antonio Hungaro DUARTE ${ }^{(b)}$

Rodrigo Ricci VIVAN ${ }^{(b)}$

(a) Universidade Sagrado Coração - USC, Pro-Rectory of Research and Post

Graduation, Bauru, SP, Brazil.

(b) Universidade de São Paulo - USP, Bauru Dental School, Department of Operative Dentistry, Endodontics and Dental Materials, Bauru, SP, Brazil.

Declaration of Interests: The authors certify that they have no commercial or associative interest that represents a conflict of interest in connection with the manuscript.

Corresponding Author:

Rodrigo Ricci Vivan

E-mail: rodrigo.vivan@fob.usp.br

DOI: 10.1590/1807-3107BOR-2015.vol29.0073

Submitted: Nov 04, 2014

Accepted for publication: Feb 18, 2015

Last revision: May 12, 2015
Abstract: This in vitro study aimed to determine the susceptibility of oral specimens and ATCC lineages of Candida albicans for five endodontic sealers, which were pure and associated with two antifungal drugs, and to analyze their effect on the physical properties. For this purpose, 30 lineages of $C$. albicans, collected from the oral cavity of patients assisted at the endodontics clinic of the Universidade Sagrado Coração, were analyzed. Yeasts susceptibility to the sealers was tested by diffusion on agar plates. Physical properties were evaluated according to the ADA specification no. 57. The pure versions of the Sealer 26, AH Plus, Endofill, Fillapex, and Sealapex demonstrated antifungal activity, with Endofill presenting the greatest inhibition zones. All cements, except for Endofill, had their antifungal actions enhanced by addition of ketoconazole and fluconazole $(\mathrm{p}<0.05)$, and the AH Plus presented the best antifungal activity. The addition of antifungal drugs did not interfere with the setting time and flowability of the sealers. It was concluded that the addition of antifungals to endodontic sealers enhanced the antimicrobial action of most cements tested without altering their physical properties.

Keywords: Antifungal Agents; Physical Properties; Root Canal Obturation; Ketoconazole; Fluconazole.

\section{Introduction}

The frequency of invasive mycoses caused by opportunistic fungal pathogens has significantly increased in the last decade. The main etiologic agents of opportunistic mycoses include the yeast that belongs to the Candida gender. ${ }^{1}$ It is estimated that $46 \%$ of healthy individuals are carriers of Candida albicans as part of their normal oral microbiota. ${ }^{2}$

As the main virulence factors, they produce proteinases, such as collagenase, aminopeptidases, alkaline phosphatase, hyaluronidase, and chondroitin sulfatase, which causes the degradation of extracellular matrix proteins. ${ }^{3}$ Several disorders affecting the oral cavity have been related to the presence of $C$. albicans, yet its effective participation in the etiopathogenesis of endodontic and/or periodontal infection is still controversial. However, the presence of this species has been detected in electron microscopic studies in asymptomatic periapical lesions. ${ }^{4,5}$

Conversely, yeasts have been detected in areas of apical root resorption, adhered by filamentous hyphae, and are able to penetrate the root dentin. ${ }^{6,7,8}$ 
Particularly, they are also related to lesions persisting after conventional endodontic treatment and cases of endodontic abscesses, where C. albicans is the most frequently identified species. ${ }^{9,10}$

Calcium hydroxide is one of the substances most widely used as an intracanal dressing. By releasing calcium and hydroxyl ions, because of the high $\mathrm{pH}$ (12.6), it provides enzymatic inhibition of bacteria, promoting satisfactory antimicrobial activity. Simultaneously, it also acts on the alkaline phosphatase release, favoring the deposition of mineralized tissues ${ }^{11}$. However, its antimicrobial activity against $C$. albicans is nearly null, ${ }^{12,13}$ and it may even favor its morphogenesis and proliferation due to the release of calcium ions. ${ }^{14}$

Because the chemical-mechanical preparation and intracanal dressing with calcium hydroxide are unable to provide complete elimination of microorganisms from the root canal system, ${ }^{15,16}$ particularly when $C$. albicans is suspected, it is important to use additional strategies to enhance the antimicrobial action of endodontic materials.

Recently, the addition of antimicrobials to endodontic sealers has been suggested, presenting favorable outcomes on cultures of Enterococcus faecalis. ${ }^{17}$ Because C. albicans also participates in endodontic infections and its elimination from the root canal system is difficult, the addition of specific antimicrobials, such as antifungals, to endodontic sealers may constitute an additional strategy. However, no studies have evaluated the effects of this incorporation on the physicochemical and antimicrobial properties of different formulas of endodontic sealers.

This study evaluated the in vitro susceptibility of several lineages of $C$. albicans (oral and ATCC) to different formulas of endodontic sealers (AH Plus, Fillapex, Sealapex, Sealer 26, and EndoFill), which are either pure or with antifungal addition (ketoconazole and fluconazole), as well as the effect of this addition on certain physical properties (setting time and flow).

\section{Methodology}

This study was approved by the Ethics Committee of the Universidade Sagrado Coração - USC (131/11). This study was conducted on 30 lineages of $C$. albicans isolated from the oral cavity of patients assisted at the
Endodontics clinic of the Dental School at the USC. A standard lineage American Type Culture Collection (ATCC) 10231 was used as a control for the study.

\section{Collection of yeast lineages}

The samples were collected using a sterile tongue depressor, scrapped on the posterior region of the tongue dorsum or on the whitish regions in the oral cavity. The tongue depressor was rinsed in a flask with hermetic seal containing $10 \mathrm{~mL}$ sterile saline until the solution was turbid.

\section{Triage of samples}

One drop of saline from the sample was placed between a glass slab and a coverslip for microscopic analysis at 40x magnification to observe the presence of blastoconidia, hyphae, or pseudo-hyphae.

\section{Culture of samples for isolation of yeasts}

Samples were plated by inoculum exhaustion on the surface of Sabouraud dextrose agar plates (Merck, Darmstadt, Germany) with the addition of $5 \%$ chloramphenicol. The plates were incubated in a mycological oven at $37^{\circ} \mathrm{C}$ for $24-48 \mathrm{~h}$. Colonies with morphological aspects of yeasts were submitted to direct examination between a glass slab and coverslip to confirm the isolation.

\section{Presumptive identification of $\mathbf{C}$. albicans}

To confirm isolation of yeasts, colonies were plated on the surface of CHROMagar Candida plates (DIFCO-BBL, Sparks, Maryland, USA) for presumptive identification of the isolated species. ${ }^{18}$ Plates were then incubated at $30^{\circ} \mathrm{C}$ for $48 \mathrm{~h}$. The principle of this medium is the pigmentation developed by the colonies because of the $\mathrm{pH}$ indicators and fermentation of specific compounds or chromogenic substrates, such as ß-glucosaminidase by hexosaminidase enzymes. In this medium, the presumptive identification for C. albicans is obtained by observing clear green pigmentation of colonies. ${ }^{18}$ The positive growth control was obtained using the strain ATCC 10231.

\section{Identification of C. albicans}

The clear green colonies isolated from the surface of the CHROMagar Candida plates were 
submitted for confirmative identification of $C$. albicans by the techniques of germinative tube production and formation of chlamydoconidia as suggested by Robles et al. ${ }^{19}$ The positive controls germinative tube production and production of chlamydoconidia were obtained using the strain ATCC 10231. Yeasts confirmed as C. albicans were stored in Sabouraud dextrose agar until susceptibility tests were performed.

\section{Activation of stored yeasts}

The stored yeasts and strain ATCC 10231 were activated on Sabouraud dextrose agar plates and incubated in a mycological oven at $37^{\circ} \mathrm{C}$ for $24-48 \mathrm{~h}$. From the plates, the colonies were transferred to tubes containing $4 \mathrm{~mL}$ Sabouraud dextrose broth (Merck, Darmstadt, Deutschland) until total turbidity of the culture broth was achieved.

\section{Evaluation of antifungal activity}

The antifungal drugs ketoconazole and fluconazole (Farmácia Veritas, Bauru, Brazil) were used in antimicrobial and physical tests. They were associated with AH Plus, Fillapex, Sealapex, Sealer 26, and EndoFill (Table 1 ) sealers, at a proportion of $0.5 \%$ by weight.

Antifungal activity was evaluated using the radial diffusion technique of substances on the surface of the Sabouraud dextrose agar plates.

For this purpose, five colonies were transferred to a tube containing $5 \mathrm{~mL}$ of Sabouraud dextrose broth and incubated at $37^{\circ} \mathrm{C}$ overnight. After growth, adjustment was made in sterile saline for optical density of $0.5 \mathrm{McF}$ arland turbidity standard $\left(1.5 \times 10^{8}\right.$ colony forming units $/ \mathrm{mL}$ ). Petri plates measuring
$150 \times 10 \mathrm{~mm}$ previously prepared with Sabouraud dextrose agar (Merck, Darmstadt, Deutschland) with a 6-mm thickness were excavated in wells with $5-\mathrm{mm}$ diameter and 3-mm depth. After adjustment of the optical density of the saline, it was plated using sterile cotton swabs on the surface of the plates, taking care to avoid plating the interior of the excavated regions. Plates were placed in an oven for 30 min to dry the culture medium surface before the placement of cements. The wells were filled using syringes and the plates were left for $2 \mathrm{~h}$ at room temperature for pre-incubation. Thereafter, they were incubated in a growth chamber at $37^{\circ} \mathrm{C}$, at adequate atmospheric conditions for $24 \mathrm{~h}$. The inhibition halos were measured with a digital pachymeter under reflected light. The same method was performed for the cements without antifungal drugs.

\section{Setting time}

The setting time was determined according to the ADA specification no. 57. Testing was performed at controlled temperature and humidity conditions, $37^{\circ} \mathrm{C} \pm 1^{\circ} \mathrm{C}$ and $95 \% \pm 5 \%$, respectively. For this analysis, sealers were previously prepared with the drugs at $0.5 \%$ of the total weight of sealers, mixed, and inserted in metallic rings with $10-\mathrm{mm}$ diameter and 2-mm thickness.

\section{Flowability}

Flowability was analyzed by the method proposed by the ANSI/ADA no. 57 . The test was performed by mixing sealers with antifungal drugs at $0.5 \%$ of the total weight and, using disposable graduated insulin syringes (a new syringe was used for each

Table 1. Endodontic sealers, compositions, and manufacturers.

\begin{tabular}{|c|c|c|}
\hline Material & Composition & Manufacturer \\
\hline MTA FillApex & Salicylate resin, diluent resin, nanoparticle resin, bismuth oxide, mineral trioxide aggregate, pigments & Angelus, Londrina, Brazil \\
\hline Sealer 26 & $\begin{array}{l}\text { Powder: bismuth trioxide, calcium hydroxide, hexamethylenetetramine, titanium dioxide } \\
\text { Liquid: epoxy bisphenol }\end{array}$ & Dentsply, Petrópolis, Brazil \\
\hline $\mathrm{AH}$ Plus & $\begin{array}{l}\text { Paste A: epoxy resin, calcium tungstate, zirconia oxide, fumed silica, pigment, } 1 \text {-adamantane amine } \\
\qquad \text { Paste B: N,N-dibenzil-5-oxa-nonandiamina-1,9,TCD diamine }\end{array}$ & Dentsply, Konstanz, Germany \\
\hline Endofill & $\begin{array}{l}\text { Powder: zinc oxide, hydrogenate resin, bismuth subcarbonate, barium sulfate, sodium borate } \\
\text { Liquid: eugenol and almond oil }\end{array}$ & Dentsply, Petrópolis, Brazil \\
\hline Sealapex & $\begin{array}{l}\text { Calcium oxide, bismuth trioxide, zinc oxide, silica particles, titanium dioxide, zinc stearate, } \\
\text { tricalcium phosphate, mixer of isobutyl salicylate }+ \text { methyl methylene salicylate }+ \text { pigment }\end{array}$ & SybronEndo, Glendora, USA \\
\hline
\end{tabular}


specimen), $0.5( \pm 0.05) \mathrm{mL}$ of cement was placed on the center of a smooth and plain glass slab, measuring $70 \times 70 \times 5 \mathrm{~mm}$. At $3 \mathrm{~min}$ after the onset of mixing, another smooth and plain glass slab was placed on the sealers and then submitted to a combined overall weight of $120 \mathrm{~g}$. Three specimens were fabricated for each cement. At 10 min after the onset of mixing, the plate and the weight were removed and the largest and smallest diameters of the circle formed by the sealers were measured with an aluminum ruler graduated in $\mathrm{mm}$.

\section{Statistical analysis}

Statistical analyses were performed by the Kruskal-Wallis method and the Dunn's test for the individual comparisons between sealers. Statistical analyses were performed using Graphpad Prism (SPSS Inc., Chicago, USA) with a significance level set at $5 \%$.

\section{Results}

Tables 2 and 3 present the inhibition zones in $\mathrm{mm}$ of antifungal activity for each sealers, pure or added to ketoconazole and fluconazole, at 24 and $48 \mathrm{~h}$, respectively.

All pure cements analyzed presented inhibition zones, with the strongest antifungal activity for the cement EndoFill. However, addition of antifungals to the sealer EndoFill did not enhance its antifungal activity. Pure AH Plus presented the smallest inhibition zone, yet the addition of ketoconazole and fluconazole enhanced its antifungal activity $(\mathrm{p}<0.05)$.

Statistical analyses by the Kruskal-Wallis method and Dunn's test for comparison demonstrated that Sealer 26, AH Plus, FillApex, and Sealapex sealers added to ketoconazole and fluconazole presented greater inhibition zones compared to the pure sealers $(p<0.05)$.

Particularly in relation to Sealapex, the antifungal activity provided by the addition of fluconazole was more favorable than the addition of ketoconazole $(p<0.05)$.

The results of the setting time are presented in Table 4 and the results of the flowability test are presented in Table 5. Different letters indicate statistically significant differences of the antifungal effect on the physical properties of each sealer $(p<0.05)$.

\section{Discussion}

The concentration of $0.5 \%$ of antifungal was determined due to the ease of preparation of the sealer for obturation, i.e., this concentration maintained the adequate handling characteristics of the material. When greater concentrations were tested, there was an increase in the thickness of the sealers and a reduction in their flowability (pilot test). Thus, the antifungal activity tests were performed on the sealers where $0.5 \%$ in total weight of ketoconazole and fluconazole were added.

Table 2. Mean and standard deviation of inhibition halos $(\mathrm{mm})$ of the sensitivity of C. albicans to sealers, pure and following addition of antifungals in $24 \mathrm{~h}$.

\begin{tabular}{lccccc}
\hline Cements & Sealer 26 & AH Plus & Endofill & Fillapex & Sealapex \\
\hline Pure & $13.4 \pm 2.01^{\mathrm{a}}$ & $8.1 \pm 1.26^{\mathrm{a}}$ & $17.4 \pm 0.72^{\mathrm{a}}$ & $11.1 \pm 1.55^{\mathrm{a}}$ & $11.6 \pm 1.19^{\mathrm{a}}$ \\
Ketoconazole $^{\prime}$ & $25.2 \pm 2.52^{\mathrm{b}}$ & $28.4 \pm 1.68^{\mathrm{b}}$ & $17.9 \pm 1.32^{\mathrm{a}}$ & $22.8 \pm 2.02^{\mathrm{b}}$ & $18.6 \pm 2.37^{\mathrm{b}}$ \\
Fluconazole $^{\|}$ & $26.2 \pm 1.89^{\mathrm{b}}$ & $28.5 \pm 1.33^{\mathrm{b}}$ & $17.8 \pm 0.93^{\mathrm{a}}$ & $22.8 \pm 1.41^{\mathrm{b}}$ & $28.1 \pm 2.05^{\mathrm{c}}$ \\
\hline
\end{tabular}

'Sealers added to $0.5 \%(\mathrm{w} / \mathrm{w})$ of ketoconazole; "Cements added to $0.5 \%(\mathrm{w} / \mathrm{w})$ of fluconazole. Different lowercase letters indicate statistically significant differences of the antifungal effect on the antimicrobial action of each sealer $(p<0.05)$.

Table 3. Mean and standard deviation of inhibition halos $(\mathrm{mm})$ of the sensitivity of C. albicans to sealers, pure and following addition of antifungals in $48 \mathrm{~h}$.

\begin{tabular}{lccccc}
\hline Cements & Sealer 26 & AH Plus & Endofill & Fillapex & Sealapex \\
\hline Pure & $13.6 \pm 1.92^{\mathrm{a}}$ & $8.2 \pm 1.10^{\mathrm{a}}$ & $18.0 \pm 0.65^{\mathrm{a}}$ & $11.1 \pm 1.26^{\mathrm{a}}$ & $11.8 \pm 1.02^{\mathrm{a}}$ \\
Ketoconazole $^{\prime}$ & $28.6 \pm 2.95^{\mathrm{b}}$ & $30.3 \pm 1.49^{\mathrm{b}}$ & $19.2 \pm 1.65^{\mathrm{a}}$ & $23.7 \pm 1.92^{\mathrm{b}}$ & $20.1 \pm 2.19^{\mathrm{b}}$ \\
Fluconazole" $^{\|}$ & $30.2 \pm 2.55^{\mathrm{b}}$ & $37.8 \pm 1.53^{\mathrm{b}}$ & $18.5 \pm 0.99^{\mathrm{a}}$ & $30.7 \pm 2.38^{\mathrm{c}}$ & $29.7 \pm 2.55^{\mathrm{c}}$ \\
\hline
\end{tabular}

Sealers added to $0.5 \%(\mathrm{w} / \mathrm{w})$ of ketoconazole; "Cements added to $0.5 \%(\mathrm{w} / \mathrm{w})$ of fluconazole. Different lowercase letters indicate statistically significant differences of the antifungal effect on the antimicrobial action of each sealer $(p<0.05)$. 
Table 4. Mean and standard deviation of setting times in minutes of sealers, pure and following addition of ketoconazole and fluconazole.

\begin{tabular}{|c|c|c|c|c|c|c|c|}
\hline \multirow{2}{*}{ Cements } & \multirow{2}{*}{$\begin{array}{l}\text { Manufacturer's } \\
\text { directions }\end{array}$} & \multicolumn{2}{|c|}{ Pure } & \multicolumn{2}{|c|}{ Ketoconazolel } & \multicolumn{2}{|c|}{ Fluconazole" } \\
\hline & & Initial & Final & Initial & Final & Initial & Final \\
\hline Sealer 26 & $720 \mathrm{~min}$ & $1000 \pm 18.93^{a}$ & $2700 \pm 76.38^{A}$ & $1200 \pm 32.15^{a}$ & $2900 \pm 45.83^{A}$ & $1100 \pm 47.26^{a}$ & $2850 \pm 20.00^{A}$ \\
\hline $\mathrm{AH}$ Plus & $480 \mathrm{~min}$ & $720 \pm 10.41^{a}$ & $1680 \pm 7.63^{\mathrm{A}}$ & $900 \pm 37.53^{a}$ & $1750 \pm 34.03^{\mathrm{A}}$ & $840 \pm 7.09^{a}$ & $1745 \pm 7.63^{\mathrm{A}}$ \\
\hline Endofill & $\mathrm{NIIII}$ & $1080 \pm 25.11^{a}$ & $2400 \pm 36.86^{A}$ & $1200 \pm 56.89^{a}$ & $2600 \pm 39.66^{A}$ & $1100 \pm 31.63^{a}$ & $2450 \pm 32.35^{A}$ \\
\hline Fillapex & $120 \mathrm{~min}$ & $4000 \pm 89.01^{a}$ & $7200 \pm 66.00^{A}$ & $2800 \pm 40.58^{b}$ & $5644 \pm 117.60^{\mathrm{B}}$ & $3000 \pm 99.23^{b}$ & $5700 \pm 66.00^{B}$ \\
\hline Sealapex & $60 \mathrm{~min}$ & $\mathrm{NFF}^{\mathrm{IV}}$ & NFF & NFF & NFF & NFF & NFF \\
\hline
\end{tabular}

'Sealers added to $0.5 \%(\mathrm{w} / \mathrm{w})$ of ketoconazole; "Cements added to $0.5 \%(\mathrm{w} / \mathrm{w})$ of fluconazole; "I' not informed; ${ }^{\mathrm{V}}$ did not fulfill. Different lowercase letters indicate statistically significant differences of the antifungal effect on the initial setting time of each sealer. Different capital letters indicate statistically significant differences of the antifungal effect on the final setting time of each sealer $(p<0.05)$.

Table 5. Mean and standard deviation in $\mathrm{cm}$ of the flow test of sealers, pure and following addition of ketoconazole and fluconazole.

\begin{tabular}{lccc}
\hline Cements & Pure & Ketoconazole $^{a}$ & Fluconazole $^{\mathrm{b}}$ \\
\hline Sealer 26 & $3.5 \pm 0.25^{a}$ & $3.4 \pm 0.15^{\mathrm{a}}$ & $3.4 \pm 0.35^{a}$ \\
AH Plus & $3.4 \pm 0.30^{\mathrm{a}, \mathrm{b}}$ & $2.9 \pm 0.25^{\mathrm{b}}$ & $3.9 \pm 0.30^{\mathrm{a}}$ \\
Endofill & $5.0 \pm 0.25^{\mathrm{a}}$ & $4.7 \pm 0.40^{\mathrm{a}}$ & $3.8 \pm 0.20^{\mathrm{b}}$ \\
Fillapex & $5.1 \pm 0.36^{\mathrm{a}}$ & $5.1 \pm 0.20^{\mathrm{a}}$ & $4.7 \pm 0.35^{\mathrm{a}}$ \\
Sealapex & $3.5 \pm 0.25^{\mathrm{a}}$ & $3.4 \pm 0.15^{\mathrm{a}}$ & $3.6 \pm 0.15^{\mathrm{a}}$ \\
\hline
\end{tabular}

a Sealers added to $0.5 \%(\mathrm{w} / \mathrm{w})$ of ketoconazole; ${ }^{\mathrm{b}}$ Cements added to $0.5 \%(\mathrm{w} / \mathrm{w})$ of fluconazole. Different lowercase letters indicate statistically significant differences of the antifungal effect on the flowability of each sealer $(p<0.05)$.

In this study, the antifungal activity test was performed by measuring the diffusion of sealers, pure and combined with antifungal drugs on the surface of Sabouraud dextrose agar. This method is widely employed by several investigators. ${ }^{20,21}$

This method allows for semi-qualitative direct comparison between materials and also indicates which sealers may present antimicrobial activity inside the root canal system. However, the results obtained by this method not only depend on the toxicity of substances on the microorganisms analyzed, but also influenced by the diffusion of components through the culture medium. ${ }^{8}$ Thus, materials with higher diffusion ability may promote bigger zones of inhibition of microbial growth. ${ }^{8}$ However, a pre-incubation period was allowed, which consists of leaving the plates for $2 \mathrm{~h}$ at room temperature to avoid diffusion of substances through the agar before incubation at adequate atmospheric conditions.

The present results revealed that all pure sealers tested present antifungal activity against $C$. albicans, based on the formation of inhibition zones on the agar surface, corroborating the results of previous studies. ${ }^{8,21}$
Sealer 26 also presented potent antifungal activity, in disagreement with previous authors. ${ }^{8,21}$ For this microorganism, using the same methodology, the differences could be related to the manipulation method, in which previous studies may have used a lower quantity of resin with less cement flow. Another reason that may explain the differences in the results would be the variable resistance of lineages employed.

Even though pure AH Plus exhibited antifungal activity, it presented the smallest zone of inhibition of microbial growth. The pure FillApex and Sealapex presented very similar inhibition zones. Some studies have suggested the addition of antimicrobial drugs to the sealers to enhance their antimicrobial activity. ${ }^{17}$

The results of this study revealed increased antifungal activity against $C$. albicans when ketoconazole and fluconazole were added to the cements. The sealers combined with these drugs exhibited increased inhibition zones on the agar compared with pure sealers ( $\mathrm{p}<0.05)$, except for the EndoFill cement. This sealer is based on zinc oxide and eugenol and may inhibit the release of antifungal drugs during the diffusion tests, which may be explained by future studies on this phenomenon.

The AH Plus demonstrated an improvement in antifungal activity against $C$. albicans when combined with ketoconazole and fluconazole. When the sealers combined with drugs were compared, fluconazole added to Sealapex revealed a significant difference in the antifungal activity $(\mathrm{p}<0.05)$ compared to the addition of ketoconazole.

Physical tests were conducted following the no. 57 ADA specification, using a $100 \mathrm{~g}$ Gillmore needle, which allowed the analysis of the setting time of the cements tested. According to the no. 57 ADA 
specification, the setting time of endodontic sealers should not be longer than $10 \%$ of the time provided in the manufacturer's instructions.

Analysis of the setting time is important to verify the release of calcium and hydroxyl ions by the sealers, consequently acting as antimicrobial and biological agents. Physical tests on the sealers, both pure and combined with antifungals, were conducted to demonstrate that the association does not interfere with them. Slight changes were observed, likely due to the powder/liquid or paste/paste ratio used for the manipulation of the sealers.

For some sealers, such as Sealer 26, the manufacturer recommends approximately two to three parts of powder to one part liquid, which may promote slight changes in the setting time. For AH Plus, this may be explained by the separation between components of pastes $\mathrm{A}$ and $\mathrm{B}$, depending on the tube region from which it is obtained..$^{13}$ For EndoFill, this may be explained by the lack of information from the manufacturer, which does not accurately determine the powder/liquid relationship that should be used. Finally, the formula of the sealer FillApex was changed in its current commercial presentation. The Sealapex sealer did not set in the present study, likely due to the absence of humidity. It contains calcium oxide in its composition and requires humidity in order to set. Our results are in accordance with Borges et al. ${ }^{22}$ The addition of antifungals interfered significantly

\section{References}

1. Pfaller MA, Diekema DJ. Epidemiology of invasive candidiasis: a persistent public health problem. Clin Microbiol Rev. 2007 Jan;20(1):133-63.

2. Weckwerth $\mathrm{PH}$, Carnietto C, Weckwerth ACVB, Duarte $\mathrm{MAH}$, Kuga MC, Vivan RC. In vitro susceptibility of oral Candida albicans strains to different $\mathrm{pH}$ levels and calcium hydroxide saturated aqueous solution. Braz Dent J. 2012;23(3):192-8

3. Panizo MM, Reviákina V, Flores Y, Montes W, González G. Actividad de fosfolipasas y protesasas en aislados clínicos de Candida spp. Rev Soc Venez Microbiol (Caracas). 2005;25(2):64-71.

4. Nair PNR, Sjogren U, Kahnberg KE, Krey G, Sundqvist G. Intraradicular bacteria and fungi in root-filled, asymptomatic human teeth with therapy-resistant periapical lesions: a in the setting time of Fillapex, where a reduction of the setting time was observed. In the other sealer, the setting time was not affected.

Flowability is another important physical property. Micro CT (computed microtomography) studies have revealed irregularities in the root canal system. ${ }^{23}$ This property is important to fill these irregular areas, as well as spaces between gutta-percha points. This study used the extensibility technique, following the no. 57 ADA dispecification. ${ }^{24}$

It was observed that the addition of ketoconazole and fluconazole at a ratio of $0.5 \%$ to the sealer affected the flowability of the AH Plus (Ketoconazole) and Endofill (Fluconazole). For the other sealers, the addition of antifungals did not affect flowability.

Therefore, it was observed that the addition of antifungals at a ratio of $0.5 \%$ to the sealers favored a stronger antifungal action for most sealers and did not interfere with some physical properties, thus constituting an option for obturation of teeth with suspected presence of fungal infection, especially in cases of treatment failure.

\section{Conclusion}

The addition of antifungal drugs enhanced the antimicrobial action of most endodontic sealers tested and interfered with the setting time of Fillapex and in the flowability of Endofill and AH Plus.

long-term light and electron microscopic follow-up study. J Endod. 1990 Dec;16(12):580-8.

5. Sen BH, Piskin B, Demirci T. Observation of bacteria and fungi in infected root canals and dentinal tubules by SEM. Endod Dent Traumatol. 1995 Feb;11(1):6-9.

6. Lomçali G, Sen BH, Cankaya H. Scanning electron microscopic observations of apical root surfaces of teeth with apical periodontitis. Endod Dent Traumatol. 1996 Apr;12(2):70-6.

7. Sen BH, Safavi KE, Spangberg LSW. Growth patterns of Candida albicans in relation to radicular dentin. Oral Surg Oral Med Oral Pathol Oral Radiol Endod. 1997 Jul;84(1):68-73.

8. Siqueira Jr JF, Favieri A, Gahyva SMM, Moraes SR, Lima KC, Lopes HP. Antimicrobial activity and flow rate of newer and established root canal sealers. J Endod. 2000 May;26(5):274-7. 
9. Waltimo TMT, Sirén EK, Torkko HLK, Olsen I, Haapasalo MPP. Fungi in therapy-resistant apical periodontitis. Int Endod J. 1997 Mar;30(2):96-101.

10. Baumgartner JC, Watts CM, Xia T. Occurrence of Candida albicans in infections of endodontic origin. J Endod. 2000 Dec;26(12):695-8.

11. Estrela C, Sidney GB, Bammann LL, Felippe Jr O. Estudo do efeito biológico do $\mathrm{pH}$ na atividade enzimática de bactérias anaeróbias. J Appl Oral Sci (Bauru). 1994;2(4):29-36.

12. Waltimo TMT, Orstavik D, Sirén EK, Haapasalo MP. Susceptibility of oral Candida species to calcium hydroxide in vitro. Int Endod J. 1999 Mar;32(2):94-8.

13. Waltimo TMT, Orstavik D, Sirén EK, Haapasalo MP. In vitro susceptibility of Candida albicans to four disinfectants and their combinations. Int Endod J. 1999 Nov;32(6):421-29.

14. Holmes AR, Cannon RD, Shepherd MG. Effect of calcium ion uptake on Candida albicans morphology. FEMS Microbiol Lett. 1991 Jan;61(2-3):187-93.

15. Nair PNR, Henry S, Cano V. Microbial status of apical root canal system of human mandibular first molars with primary apical periodontitis after "one-visit" endodontic treatment. Oral Surg Oral Med Oral Pathol Oral Radiol Endod. 2005 Feb;99(2):231-52.

16. Nair PNR. On the causes of persistente apical periodontitis: a review. Int Endod J. 2006 Apr;39(4):249-81.

17. Hoelscher AA, Bahcall JK, Maki JS. In vitro evaluation of the antimicrobial effects of a root canal sealer-antibiotic combination against Enterococcus faecalis. J Endod. 2006 Feb;32(2):145-7.
18. Yücesoy M, Esen N, Yulug, N. Use of chromogenic tube and methyl blue-Sabouraud agar for the identification of Candida albicans strains. Kobe J Med Sci. 2001 Aug;47(4):161-7.

19. Robles MG, Ausejo FU, Cavero JC. Manual de procedimientos y técnicas de aboratorio para la identificación de los principales hongos oportunistas causantes de micoses humanas. Lima: Ministério de Salud, Instituto Nacional de Salud; 2007.

20. Leonardo MR, Silva LAB, Tanomaru-Filho M, Bonifácio KC, Ito IY. In vitro evaluation of antimicrobial activity of sealers and pastes used in endodontics. J Endod. 2000 Jul;26(7):391-4.

21. Gomes BPFA, Pedroso JA, Jacinto RC, Vianna ME, Ferraz CCR, Zaia AA, et al. In vitro evaluation of the antimicrobial activity of five root canal sealers. Braz Dent J. 2004;5(1):30-5.

22. Borges RP, Sousa-Neto MD, Versiani MA, Rached-Júnior FA, De-Deus G, Miranda CE, et al. Changes in the surface of four calcium silicate-containing endodontic materials and an epoxy resin-based sealer after a solubility test. Int Endod J. 2012 May;45(5):419-28.

23. Villas-Bôas MH, Bernardineli N, Cavenago BC, Marciano M, Del Carpio-Perochena A, Moraes IG, et al. Micro-computed tomography study of the internal anatomy of mesial root canals of mandibular molars. J Endod. 2011 Dec;37(12):1682-6.

24. Resende LM, Rached-Junior FJA, Versani MA, Souza-Gabriel AE, Miranda CES, Silva-Sousa YTC, et al. A comparative study of physicochemical properties of AH Plus, Epiphany, and Epiphany SE root canal sealers. Int Endod J. 2009Sep;42(9):785-93.

25. Baldi JV, Bernardes RA, Duarte MAH, Ordinola-Zapata R, Cavenago BC, Moraes JC, et al. Variability of physicochemical properties of an epoxy resin sealer taken from different parts of the same tube. Int Endod J. 2012 Oct;45(10):915-20. 